\title{
Strength Analysis of Porous YSZ Ceramics With the Same Porosity and Different Pore Structure
}

\section{ying lang ( $\nabla$ ylang1977@aliyun.com )}

national engineering research center for domestic \& building ceramic

xin dai

Jingdezhen Ceramic Institute

lin zhao

Jingdezhen Ceramic Institute

Hong-Kang wei

Jingdezhen Ceramic Institute

chang-an wang

Tsinghua University Department of Materials Science and Engineering: Tsinghua University School of Materials Science and Engineering

\section{Research Article}

Keywords: porous materials, porosity, compressive strength

Posted Date: January 11th, 2021

DOI: https://doi.org/10.21203/rs.3.rs-142223/v1

License: (a) (i) This work is licensed under a Creative Commons Attribution 4.0 International License. Read Full License 


\section{Abstract}

Porous YSZ ceramics with different pore structure were prepared by volume limiting foaming technology. Accurate porosity could achieve by this technology[1], so all samples were adjusted to density of $1 \mathrm{~g} / \mathrm{m}^{3}$ (porosity of about $82.6 \%$ ). For the same density, the influence of porosity change on the strength was excluded. The effects of different pore structure on mechanical properties (compressive strength, strengthdeformation curve and Young's modulus) were studied. The results showed that for porous ceramics with uniform pores the larger the pore size was, the smaller the Young's modulus and the lower the strength was. In addition, for samples with mix pores (large pore and small pore), when the volume fraction of macropores is large, the strength is the same as that of porous ceramics with uniform small pore size structure; when the volume fraction of small pores is large, the strength is the same as that of porous ceramics with uniform large pore size structure.

\section{Introduction}

Porous ceramics have high specific surface area, lightweight and low thermal conductivity for their unique pore structure. They are widely used in thermal resistance materials, sound absorption materials, catalyst support and other fields[2-5]. To get lighter ceramics with larger specific surface area and lower thermal conductivity, it is hoped that the porosity of porous ceramics can be further reduced. Many practicable processes have been studied and developed, such as pore forming agents, controlled sintering, sacrificial template, gelcasting, direct foaming [6-15]. However, the porosity and strength of porous ceramics are contradictory. Higher porosity is often accompanied by low strength for porous ceramics.

Many work has been done on the relationship between strength and structure[16-24]. Some empirical formulas and fracture models have been proposed. However, it is difficult to have corresponding experiments to verify. When some conditions in the preparation process are changed, the pore structure and porosity both changed. So the effect of porosity and pore structure on sample strength cannot be studied separately. At present, it is considered that porous ceramics with uniform and smaller pores have higher strength under the same porosity. However, the theoretical basis for the formation of this law is not clear.

Limited volume foaming process is a preparation technology of porous ceramics which can accurately control the porosity of samples[1]. The foaming is limited in the ball milling tank, and the space in the ball milling tank is fixed. Due to the determined total volume of the foam, foaming degree can be accurately controlled. Through calculation, the certain porosity can be earned by changing the amount of the slurry.

In our early work [25], porous ceramics with different pore structure and porosity were prepared. In this paper, porous YSZ ceramics with different pore structure (the size and number of pores) were prepared by different speed of stirring and the doping amount of foaming agent. Through the volume limiting foaming technology, their porosity can be adjusted to the same level. Thus, the mechanical properties of porous ceramics with different pore structure under the same porosity can be compared to find out their regularity. By comparing the change rule of pore structure and strength, the change law of pore structure and strength of porous ceramics was obtained. 


\section{Experimental Procedure}

YSZ powder (mean particle size is about 0.1[m, AR., Jiangxi Size Materials Co., Ltd.) was used as raw material. Isobam 104\# (Kuraray Co., Ltd. Osaka, Japan) and Sodium dodecyl sulfate (SDS, Sinopharm Chemical ReagentCo., Ltd) were used as dispersant and pore-foaming agent. Deionized water was used as solvent.

$90 \mathrm{ml}$ slurry was prepared with 25 vol\% YSZ powder, $4 \mathrm{wt} \%$ isobam 104 (IB) premix solution by ball milling with a rotary speed of $450 \mathrm{r} / \mathrm{min}$ for 2 hours. Subsequently, SDS solution ( $2.5 \mathrm{wt} \%$ of slurry) of different concentration (1.5-6 wt\%) was added into the slurry to generate foams at room temperature. Rotary speed was set to $350 \mathrm{r} / \mathrm{min}$ for 10 minutes to mix slurry uniform and then $450-500 \mathrm{r} / \mathrm{min}$ for 10 minutes to generate bubbles. The foamed slurries were immediately cast into plastic molds (Cylinder with a diameter of $22 \mathrm{~mm}$ ). In order to solidify the foamed slurry rapidly, the moulds were placed in a freeze dryer to freeze at $-50^{\circ} \mathrm{C}$ for 2 hours, and then the solvent contained in the sample was removed by sublimation at $-50^{\circ} \mathrm{C}$ in vacuum for 24 hours. After demoulding, the dried green bodies were calcined at $500^{\circ} \mathrm{C}$ for 2 hours to remove the organics, and then sintered at $1500^{\circ} \mathrm{C}$ for 2 hours.

In order to obtain different pore structure, six processes were selected to prepare porous YSZ ceramics which are shown in Table 1. Initial slurry dosage was $90 \mathrm{ml}$. Then porosity and density were measured. If the density of the sample was tested as $\rho\left(\mathrm{g} / \mathrm{m}^{3}\right)$, then the amount of slurry was adjusted to $90 / \rho \mathrm{ml}$, repeated the process of stirring, foaming, freeze-drying and sintering, and then porous YSZ ceramic material with density of $1 \mathrm{~g} / \mathrm{m}^{3}$ could be obtained. In this way, six kinds of porous YSZ ceramic samples with the same porosity and different pore structures were prepared.

Microstructure was observed using scanning electron microscope (SEM, JSM 6700F, JEOL, Tokyo, Japan). Porosity was measured by calculating the differences between the theoretical density and the actual density. Compressive strength was measured on cylinder samples $(\$ 20 \mathrm{~mm}$ and height $20 \mathrm{~mm})$ and loaded with a crosshead speed of $0.5 \mathrm{~mm} / \mathrm{min}$ using CSS-2220 test machine. Four samples were used to determine the average porosity and compressive strength.

Pore size information was obtained by image analysis of SEM images. In the low magnification scanning image, the diameters of all pores in an area $(840 \mu \mathrm{m} \times 1200 \mu \mathrm{m})$ were measured. Volume of all pores in each aperture range were calculated and accumulated. Then the pore size distribution was obtained in this paper.

\section{Results And Discussion}

\subsection{Density and porosity}

Table 2 shows the density and porosity of the porous YSZ ceramic samples. As illustrated the density is about $1 \mathrm{~g} / \mathrm{m}^{3}$, the porosity is the same. In this paper, the influence of porosity change on the strength is excluded, the change of compressive strength and Young's modulus is only related to the pore structure.

\subsection{Microstructure and pore size distribution}


The microstructure of the samples is shown in Fig. 1. The samples with different fabricate conditions have different pore structures. Compared with Sample 1 and Sample 2, the pore diameter of Sample 3 decreased obviously. The increase of stirring speed breaks the large bubbles, resulting in the decrease of pore diameter. The pore diameter of Sample 4 is obviously larger than that of other samples, which may be due to the decrease of the number of pores with less foaming agent.

The pore size distribution curves are shown in Fig.2. It can be seen that the pore size of Sample 3 is obviously smaller and the pore size of Sample 4 is obviously larger than that of other samples. This is consistent with the microscopic images of SEM.

Meanwhile the pore size distribution curves of Samples 1,3 and 4 are continuous. It can be considered that Samples 1, 3 and 4 have continuous and uniform pore structure. And their pore sizes in descending order are Sample 3₫Sample $1 \llbracket$ Sample 4. In addition, for the Samples 2,5 and 6 , the distribution range of macropores and small pores is separated, so it can be considered that Samples 2,5 and 6 have mixed pore structure with macropores and small pores. Sort from large to small according to the proportion of pores to volume, the order is Sample 2₫Sample 5₫Sample 6.

Therefore, the samples can be divided into two groups for comparison: (1) Samples 1,3,4 with uniform pore; and (2) Samples 2, 5 and 6 with mixed pores.

\subsection{Mechanical properties of the samples with uniform pore size}

The mechanical properties of Samples 1, 3 and 4 with continuous pore size distribution are compared in Table 3, in which the highest peak in the pore size distribution was taken as the pore size, and the Young's modulus was calculated from the slope of the stress-strain curves (Fig. 3). It can be seen the compressive strength decrease with the increase of pore size. Therefore, for the porous ceramics with uniform pore structure, the mechanical properties are susceptible to the pore size under the certain porosity. This result is consistent with the present theory.

However, it can also be seen that the Young's modulus decreases greatly with the increase of pore size. According to the traditional theory, the elastic modulus of porous ceramics is only related to the porosity of samples. Obviously, the experimental results are not consistent with this theory.

\subsection{Mechanical properties of the samples with mix pore size}

The mechanical properties of samples with mix pore size are compared in Table 4, in which the pore size of macropores and small pores, the volume ratio (the ratio of the peak value of macropores to small pores) are recorded. It can be seen from Table 4 that the changes of compressive strength and Young's modulus have no obvious regularity with the pore size of macropores or small pores. However, the strengths have obvious laws with the volume ratio of macropores and small pores. With the decrease of the volume ratio, the compressive strength decreases and the Young's modulus increases. Therefore, when the porosity is the same, the more macropores, the higher the strength and the lower the Young's modulus.

\subsection{Comparison of properties between samples with uniform pore and mix pore}


Compared with Sample 1 and 4, the strength of Sample 6 is roughly equivalent to that of the sample with average pore size of $210 \mu \mathrm{m}$ (the pore size of the macropores in Sample 6).

It is worth noting that compared with Sample 2, Sample 3 is better both in pore size and uniformity. From the existing theoretical analysis, the strength of Sample 3 should be greater than that of Sample 2. However, in fact, the strength of Sample 3 has not increased, but is slightly smaller than that of Sample 2.

Further study shows the small pore size $(120 \mu \mathrm{m})$ of Sample 2 is slightly smaller than pore size $(130 \mu \mathrm{m})$ of Sample 3. It can be implied the strength of the samples with mixed pores is similar to that of porous ceramics with uniform small-pore-size pores.

It can be seen that the Young's modulus of the sample with mixed pores(56.6MPa, 60.7MPa, 61.9MPa) is

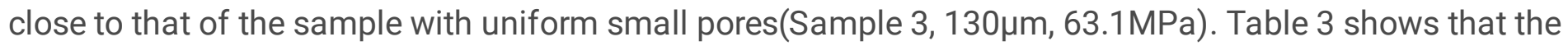
elastic modulus of large pore structure is low, which leads to less elastic force when it is compressed and deformed. Therefore, the load-bearing of mixed pore sample is mainly small pore structure. When the sample continues to deform under pressure, the small pore structure will extrude the large pore structure. When there are more atmospheric pores, the large pore structure has enough space to withstand the extrusion of the small pore structure. Therefore, the small pore structure will be destroyed first. In this case, the strength of the sample is related to the structure of small pores. However, when there are few atmospheric pores, the space occupied by the macropores is limited, and the macropores are squeezed by a large number of small pores, which leads to the destruction of the macropores prior to the small pores. At this time, the macropore structure determines the strength of the sample.

From the above experimental results and analysis, it can be seen that for porous ceramics with uniform pores, the larger the pore size, the lower the strength (as shown in Fig. 4). For the samples with mixed pore structure of two sizes of pores, i.e. large pore (pore size $\mathbf{R}$ ) and small pore (pore size $\mathbf{r}$ ), the strength is between that of the samples with uniform pore size $\mathbf{R}$ and that with uniform pore size $\mathbf{r}$. The strength decreases with the decrease of the volume fraction of macropores. When the volume fraction of macropores is large, the strength is the same as that of porous ceramics with uniform pore structure with $\mathbf{r}$ pore size. When the volume fraction of small pores is large, the strength is the same as that of porous ceramics with uniform pore structure with $\mathbf{R}$ pore size.

In general, above conclusions are earned under the condition of few data. However, it is difficult to obtain porous ceramics with more different pore structure at the same porosity. At the same time, if the pore size and compressive strength of Samples 1, 3 and 4, as well as the micropore size and compressive strength of Sample 2, and macropore diameter and compressive strength of Sample 6, an ideal straight line will be obtained, which indirectly proves the above conclusions(Fig. 5).

\section{Conclusions}

Porous YSZ ceramics with the same porosity but different pore structure were prepared by limited volume foaming process, so that the influence of porosity could be ignored and the effect of pore structure on mechanical properties was considered separately. By comparing the micro morphology, pore distribution, 
compressive strength-deformation curve, strength and Young's modulus of the porous YSZ ceramics, the following conclusions can be drawn.

(1) For uniform pores, the strength of samples decreases with the increase of pore size. For samples with mixed pores, the strength decreases with the decrease of the volume fraction of macropores.

(2) The Young's modulus of the samples with uniform pores is related to the size of the pores. The larger the pore size is, the smaller the Young's modulus is. For samples with mixed pores, Young's modulus is close to that of the sample with uniform small pores, and with the decrease of the volume fraction of large pores, Young's modulus increases slightly.

(3) For samples with same porosity, the strength of ceramics with mix pore is between that of uniform pore structure ceramics with large pore size and small pore size. When the volume fraction of macropores is small, the strength is equal to the sample with uniform large pore size. When the macropore volume is large, the strength is equal to that of the sample with the uniform small pore size.

\section{Declarations}

\section{Acknowledgements}

This work was financially supported by Department of Education of Jiangxi Province (Project No. GJJ180714).

\section{References}

[1] Lang Y, Tian CJ, Dai X, et al. Preparation of YSZ porous ceramics with precise porosity control. Int J Appl Ceram Tec 2020, DOI:10.1111/ijac.13431

[2] Eom JH, Kim YW, Raju S, Processing and properties of macroporous silicon carbide ceramics: a review. $J$ Asian Ceram Soc 2013,1: 220-242

[3] Studart AR, Gonzenbach UT, Tervoort E, et al. Processing routes to macroporous ceramics: a review. J Am Ceram Soc 2006, 89: 1771-1789.

[4 Colombo P, Ceramic foams: fabrication, properties and applications. Key Eng Mater Trans Tech Pub 2002, 1913-1918.

[5] Colombo P, Conventional and novel processing methods for cellular ceramics. Philos. Trans 2006, 364: 109.

[6]Li F, Huang X, Liu JX, Sol-gel derived porous ultra-high temperature ceramics. J Adv Ceram 2020, 9: 1-16.

[7]Ye XL, Chen ZF, Ai SF, Porous SiC/melamine-derived carbon foam frameworks with excellent electromagnetic wave absorbing capacity. J Adv Ceram 2019, 8: 479-488 
[8] Dresler M, Reinsch S, Schadrack R, et al. Burnout behavior of ceramic coated open cell polyurethane (PU) sponges. J Eur Ceram Soc 2009, 29: 3333-3339.

[9] Yao X, Yang Y, Liu X, et al. Effect of recoating slurry compositions on the microstructure and properties of SiC reticulated porous ceramics. J Eur Ceram Soc 2013, 33: 2909-2914.

[10] Alem A, Pugh MD, Drew RA, Open-cell reaction bonded silicon nitride foams: fabrication and characterization. J Eur Ceram Soc 2014, 34: 599-609.

[11] Xia Y, Zeng YP, Jiang D, Mechanical and dielectric properties of porous $\mathrm{Si}_{3} \mathrm{~N}_{4}$ ceramics using PMMA as pore former. Ceram Int 2011, 37: 3775-3779.

[12] Zhang LY, Zhou DL, Chen Y, et al. Preparation of high open porosity ceramic foams via direct foaming molded and dried at room temperature. J Eur Ceram Soc 2014, 34:2443 2452.

[13] Ahmad R, Ha JH, Song IH, Particle-stabilized ultra-low density zirconia toughened alumina foams. J Eur Ceram Soc 2013, 33: 2559-2564.

[14] Fukushima M, Nakata M, Zhou Y, et al. Fabrication and properties of ultra highly porous silicon carbide by the gelation-freezing method. J Eur. Ceram Soc 2010, 30:2889-2896.

[15]Ren JT, Ying W, Zhao J, et al. High-strength porous mullite ceramics fabricated from particle stabilized foams via oppositely charged dispersants and surfactants. Ceram Int 2019, 45: 6385-6391

[14]Du ZP, Yao DX, Xia YF, et al. The high porosity silicon nitride foams prepared by the direct foaming method. Ceram Int 2019, 45: 2124-2130

[15]Han L, Wang JK, Li FL, et a风Low-temperature preparation of $\mathrm{Si}_{3} \mathrm{~N}_{4}$ whiskers bonded/reinforced SiC porous. J Eur Ceram Soc 2018, 38: 1210-1218

[16]Liu jj, Huo WL, Zhang XY, et al. Optimal design on the high-temperature mechanical properties of porous alumina ceramics based on fractal dimension analysis. J Adv Ceram 2018, 7: 89-98.

[17]Chen $\mathrm{JJ}$, Chen $\mathrm{JX}$, Zhang $\mathrm{H}$, Microstructure and mechanical properties of h-BN/ $\mathrm{Yb}_{4} \mathrm{Si}_{2} \mathrm{O}_{7} \mathrm{~N}_{2}$ composites. J Adv Ceram 2018, 7: 317-324

[18]Wang RZ, Wang S, Li DY, et al. Temperature dependence of the fracture strength of porous ceramic materials. Ceram Int 2020, 46:11311-11316

[19]Ren JT, Ying W, Zhao J, et al. High-strength porous mullite ceramics fabricated from particle-stabilized foams via oppositely charged dispersants and surfactants. Ceram Int 2018, 10.1016/JceramInt2018.12.125

[20]Deng XG, Ran SL, Han L, et al. Foam-gelcasting preparation of high-strength self-reinforced porous mullite ceramics. J Eur Ceram Soc 2017, 37: 4059-4066 
[21]Huo WL, Zhang XY, Chen YG, et al. Mechanical strength of highly porous ceramic foams with thin and lamellate cell wall from particle-stabilized foams. Ceram Int 2018, 44:5780-5784

[22]Kim EH, Oh YS, Jung YG. Relationship between net work structure and fracture strength of ceramic core in a gel-casting process. Ceram Int 2015, 41: 3396-3399

[23]Carolina T, Chayuda C, David ED, et al. Mechanical strength and damage to lerance of highly porous alumina ceramics produced from sintered particles tabilized foams. Ceram Int 2016, 42: 8478-8487 [24] Hou DW, Li DY,Hua PC, et al. Statistical modelling of compressive strength controlled by porosity and pore size distribution for cementitious materials. Ceram Int 2018, 10.1016/Jcemconcomp.2018.10.012 [25]Lang Y, Zhao L, Dai X, et al. Preparation of porous YSZ ceramics by ball milling foaming-freeze drying process. Ceram Int 2020, 46:9834-9838

\section{Tables}

Table 1 Experiment parameters of six process.

\begin{tabular}{|lllllll|}
\hline No. & 1 & 2 & 3 & 4 & 5 & 6 \\
\hline $\begin{array}{l}\text { Mixing speed of } \\
\text { ball milling }(\mathrm{r} / \mathrm{m})\end{array}$ & 450 & 500 & 550 & 500 & 500 & 500 \\
\hline Foaming agent concentration $(\mathrm{wt} \%)$ & 3 & 3 & 3 & 1.5 & 4.5 & 6 \\
\hline
\end{tabular}

Table 2 Density and porosity of samples in six process.

\begin{tabular}{|lllllll|}
\hline No. & 1 & 2 & 3 & 4 & 5 & 6 \\
\hline $\begin{array}{l}\text { Density } \\
\llbracket \mathrm{g} / \mathrm{m}^{3} \square\end{array}$ & $1.011 \pm 0.006$ & $1.050 \pm 0.019$ & $1.007 \pm 0.009$ & $1.019 \pm 0.026$ & $1.005 \pm 0.016$ & $1.007 \pm 0.015$ \\
\hline $\begin{array}{l}\text { Porosity } \\
\llbracket \% \rrbracket\end{array}$ & $82.71 \pm 0.10$ & $82.06 \pm 0.33$ & $82.79 \pm 0.15$ & $82.59 \pm 0.44$ & $82.82 \pm 0.27$ & $82.78 \pm 0.25$ \\
\hline
\end{tabular}

Table 3 Property comparison of samples with continuous pore size.

\begin{tabular}{|llll|}
\hline No. & 3 & 1 & 4 \\
\hline Pore Size $₫ \mu \mathrm{m} \otimes$ & 130 & 160 & 260 \\
\hline Compressive strength $\varangle \mathrm{MPa} \rrbracket$ & $2.29 \pm 0.37$ & $2.10 \pm 0.39$ & $1.32 \pm 0.39$ \\
\hline Young's modulus $(\mathrm{MPa})$ & 63.1 & 49.3 & 34.5 \\
\hline
\end{tabular}

Table 4 Property comparison of samples with mix pore size. 


\begin{tabular}{|llll|}
\hline No. & 2 & 5 & 6 \\
\hline Macro pore Size $₫ \mu \mathrm{m} \rrbracket$ & 200 & 210 & 210 \\
\hline Micro pore Size $\varangle \mu \mathrm{m} \rrbracket$ & 120 & 170 & 170 \\
\hline Volume ratio of large and small pores & 1.94 & 1.26 & 0.74 \\
\hline Compressive strength $\varangle \mathrm{MPa} \rrbracket$ & $2.39 \pm 0.30$ & $2.03 \pm 0.34$ & $1.67 \pm 0.38$ \\
\hline Young's modulus $(\mathrm{MPa})$ & 56.6 & 60.7 & 61.9 \\
\hline
\end{tabular}

\section{Figures}
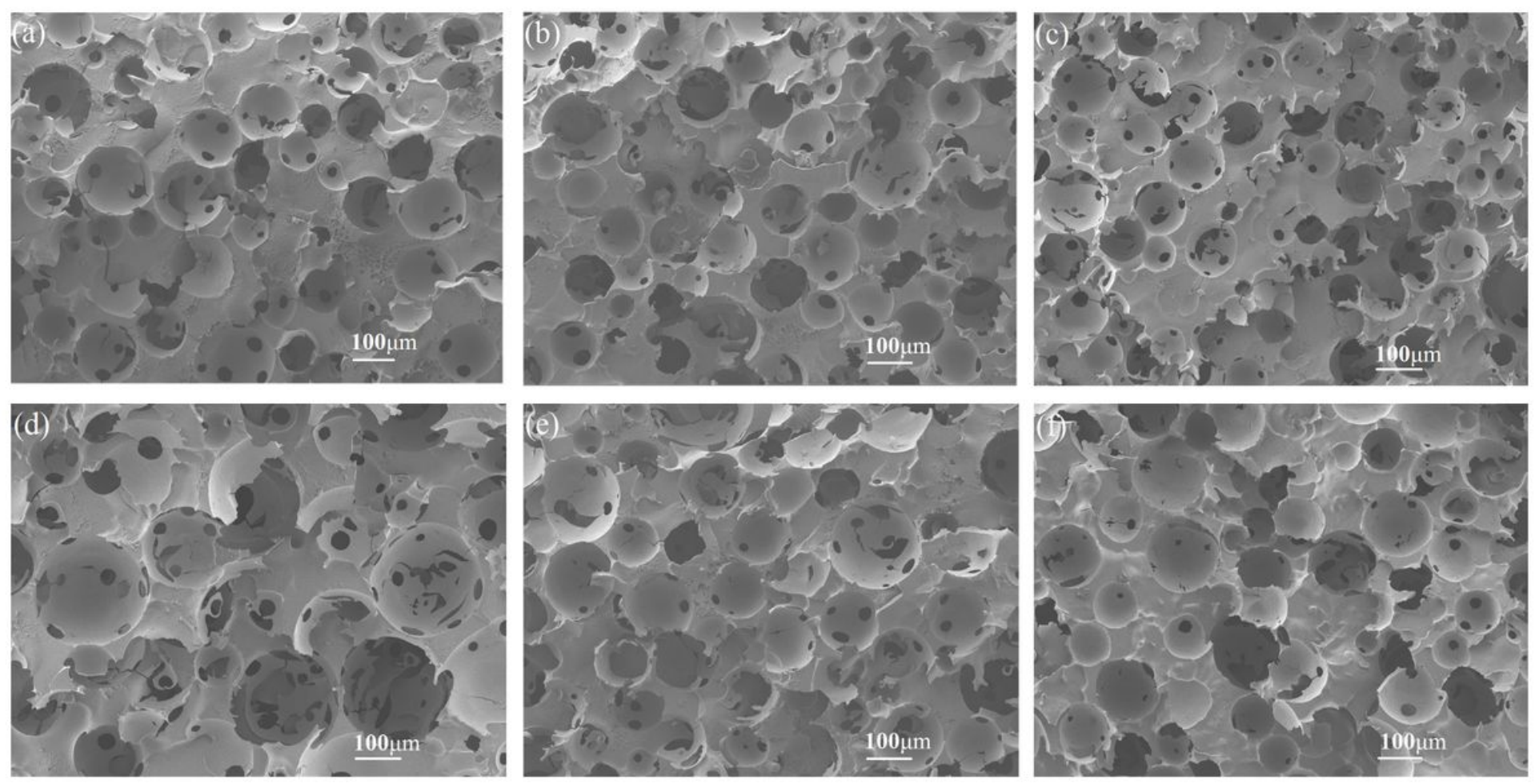

\section{Figure 1}

Section morphology of sintered samples with different fabricate process: (a) Sample 1, (b) Sample 2, (c) Sample 3, (d) Sample 4, (e) Sample 5, (f) Sample 6 


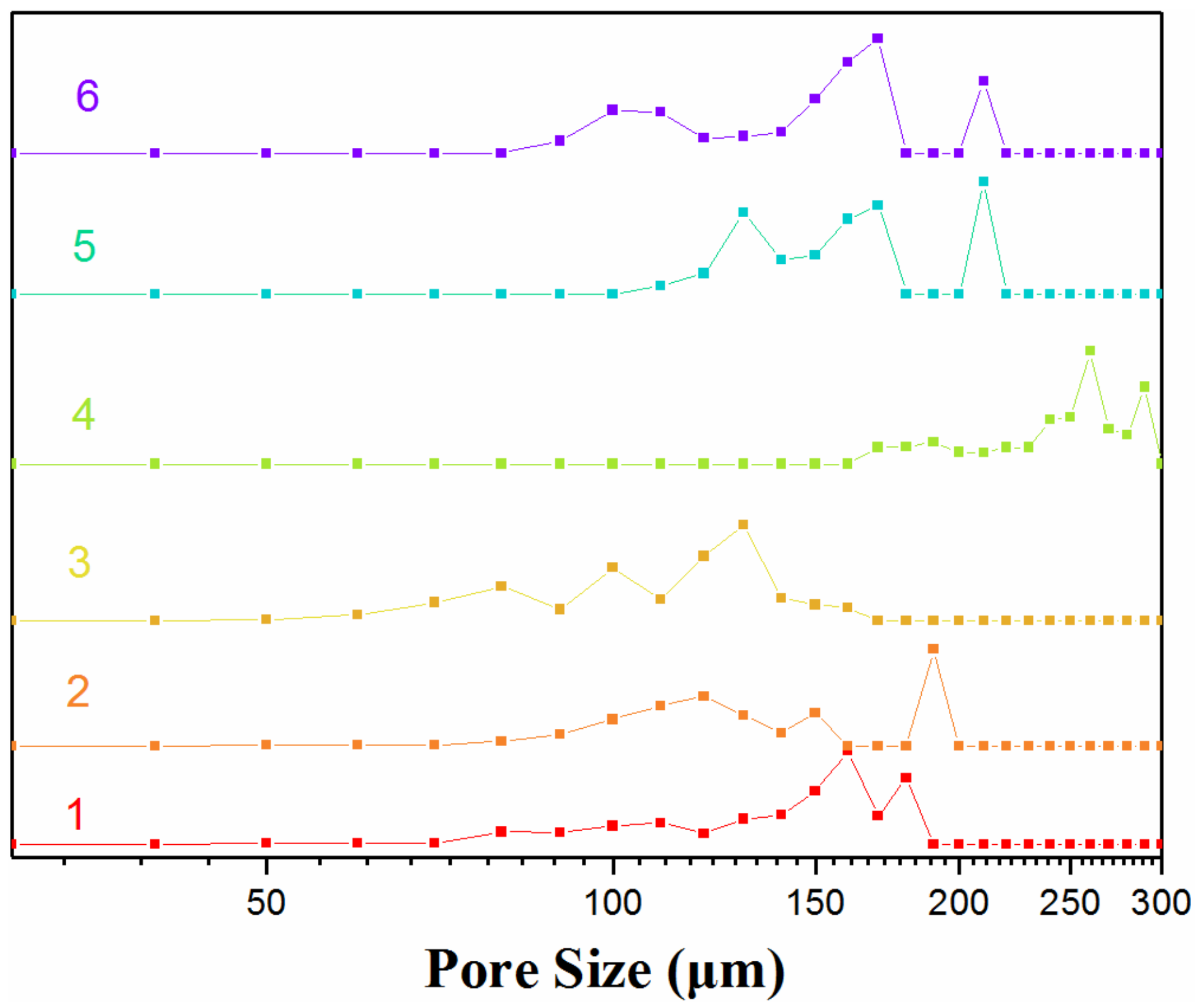

Figure 2

Size distribution of Sample 1-6 

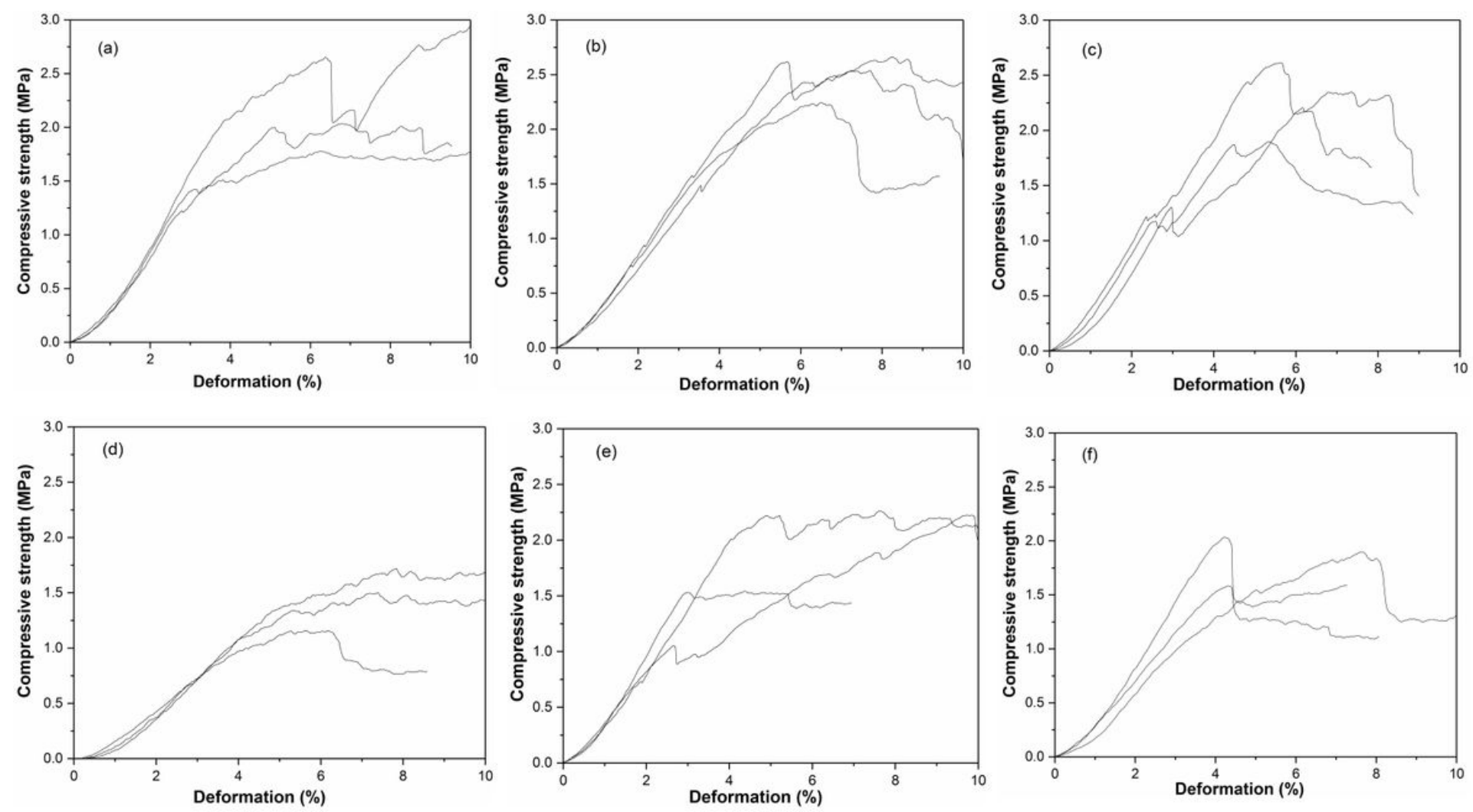

\section{Figure 3}

Compressive strength varies with deformation of Sample 1-6: (a) Sample 1, (b) Sample 2, (c) Sample 3, (d) Sample 4, (e) Sample 5, (f) Sample 6 


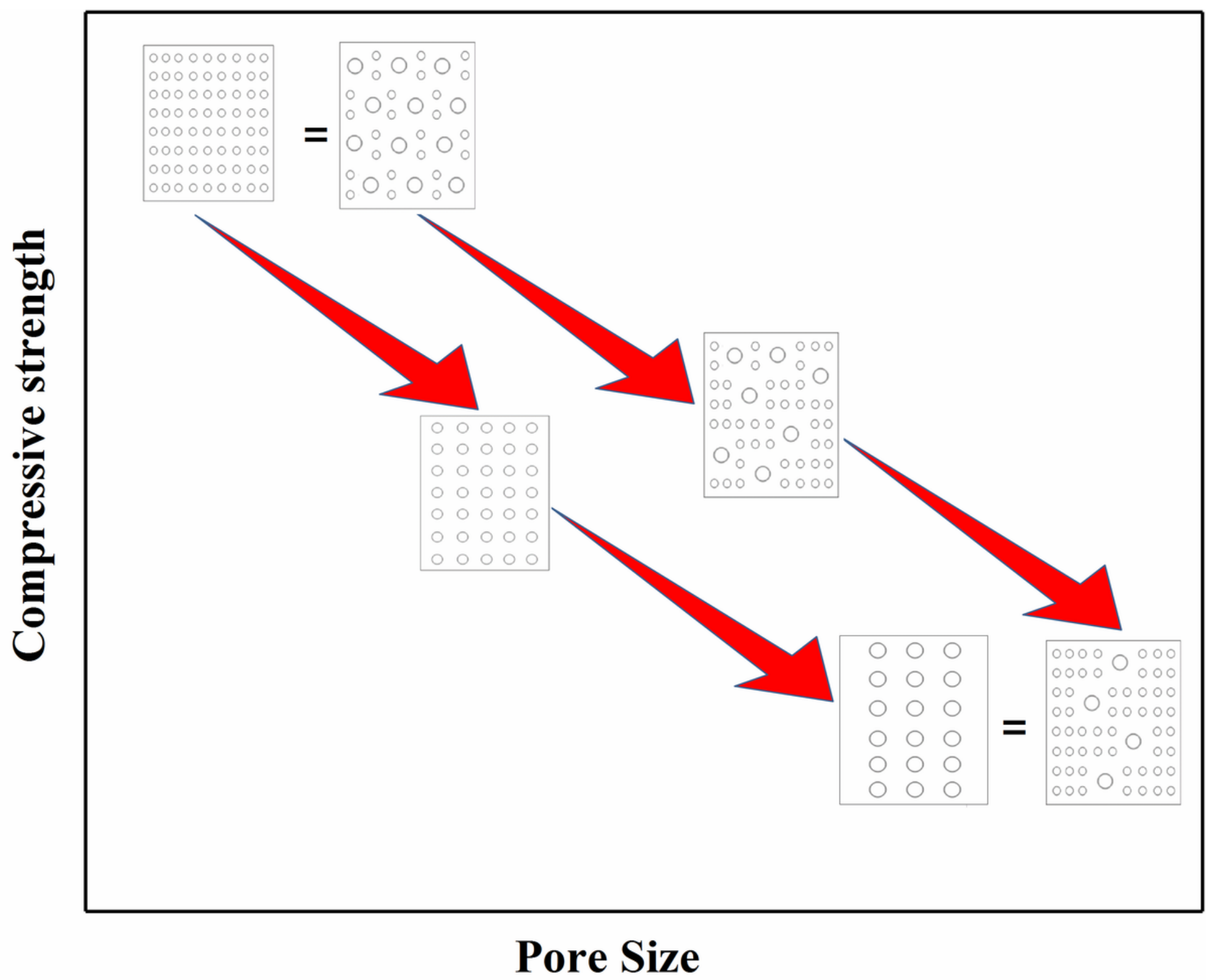

Figure 4

Chat of relationship between compressive strength and pore size 


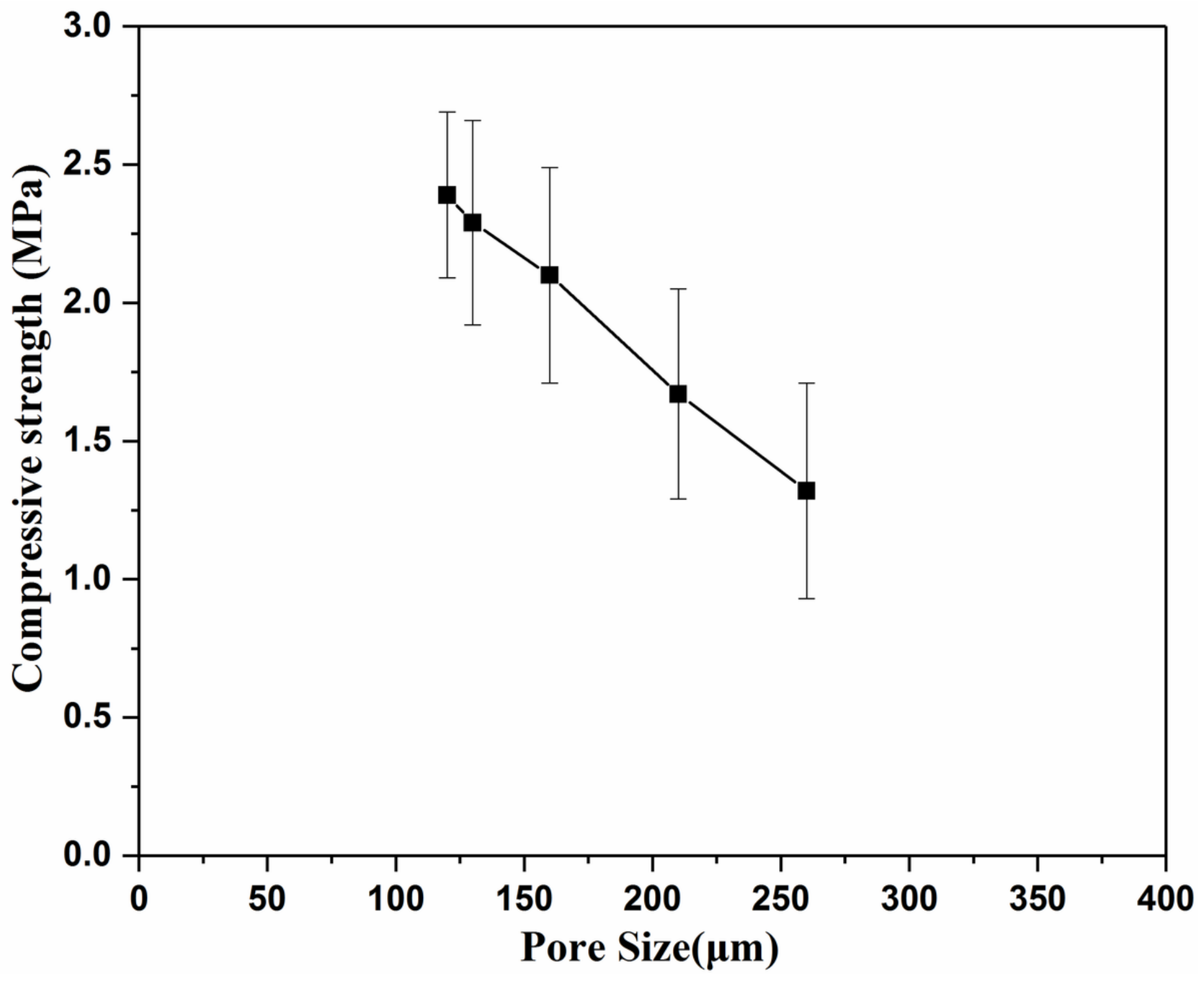

Figure 5

Relationship between compressive strength and pore size of Sample 1, 3, 4 and Sample 2(micropore) Sample 6(macropore) 